\title{
Preference for Nature in Urbanized Societies: Stress, Restoration, and the Pursuit of Sustainability
}

\author{
Agnes E. van den Berg* \\ Wageningen University \\ Terry Hartig \\ Uppsala University

\section{Henk Staats} \\ Leiden University
}

Urbanicity presents a challenge for the pursuit of sustainability. High settlement density may offer some environmental, economic, and social advantages, but it can impose psychological demands that people find excessive. These demands of urban life have stimulated a desire for contact with nature through suburban residence, leading to planning and transportation practices that have profound implications for the pursuit of sustainability. Some might dismiss people's desire for contact with nature as the result of an anti-urban bias in conjunction with a romantic view of nature. However, research in environmental psychology suggests that people's desire for contact with nature serves an important adaptive function, namely, psychological restoration. Based on this insight, we offer a perspective on an underlying practical challenge: designing communities that balance settlement density with satisfactory access to nature experience. We discuss research on four issues: how people tend to believe that nature is restorative; how restoration needs and beliefs shape environmental preferences; how well people actually achieve restoration in urban and natural environments; and how contact with nature can promote health. In closing, we consider urban nature as a design option that promotes urban sustainability.

We live in an urbanized world. At present, about $75 \%$ of the population in developed countries lives in dense urban areas (Habitat, 2001). In theory,

\footnotetext{
* Correspondence concerning this article should be addressed to A. E. van den Berg, Wageningen University and Research Centre, P.O. Box 47, 6700 AA, Wageningen, The Netherlands [e-mail: agnes.vandenberg@wur.nl].
} 
high-density cities offer many opportunities for sustainability, such as reductions in car use, and increases in resource efficiency, accessibility, and economic viability (Jenks, Burton, \& Williams, 1996). In practice, however, it has been difficult to realize these opportunities (Burgess, 2000). As a result, many cities are still far removed from the safe, clean, and livable environments they theoretically could be.

One barrier to achieving urban sustainability is formed by psychological factors. Urban life in general, and urban stressors such as noise from traffic, fear of crime, and crowding, in particular, may motivate people to look for greener grasses in the suburbs. Research on restorative environments indicates that this search involves more than merely a romantic idealization of nature (Hartig, 1993; Kaplan \& Kaplan, 1989). Numerous studies have demonstrated that contact with natural environments offers a relatively effective way of obtaining restoration from stress and mental fatigue compared to ordinary outdoor urban environments (Health Council of The Netherlands, 2004). However, continuous residential mobility to the urban periphery engenders planning and transportation practices that thwart sustainability. Moreover, with ongoing urban sprawl, individual residents may come to suffer from progressively limited access to nature and decreased quality of the nature experiences they had originally sought.

In this article, we first discuss the urban sustainability challenge and the limitations of the compact city model as a solution to this challenge. In particular, we elaborate on a common desire for contact with nature as a barrier to the realization of urban sustainability through compact building. We then discuss two alternative perspectives on people's desire for contact with nature: rural romanticism and needs for restoration. The relevance of the latter explanation is illustrated by a review of recent empirical findings. In closing, we consider how urban greenery might figure in residential design options that promote urban sustainability considered in social and psychological as well as physical terms.

\section{A Psychological Challenge to Urban Sustainability}

Recent decades have witnessed increasing recognition of the significance of global environmental problems, and the importance of local action in both creating and addressing these problems. "Sustainability" has emerged as a widely held and necessary notion to guide societal development. In general, sustainability can be defined as the ability of a system to "meet the needs of the present without compromising the ability of future generations to meet their own needs" (World Commission on Environment and Development [WCED], 1987). Cities and urban regions play an important role in the sustainability debate. Cities contribute to a large extent to global environmental problems that threaten human life, while at the same time people living in cities are confronted with interrelated local problems 
such as environmental pollution, health risks, social segregation, and meeting economic growth targets. Consequently, strategies to make cities more sustainable have been formulated by governments and institutions all over the world (e.g., European Environment Agency, 1995). These strategies focus on the protection of environmental resources (e.g., air quality, biodiversity) as well as social and economic resources (e.g., livability, prosperity).

Some well-known efforts to achieve urban sustainability have focused on compactness as a key factor to maintaining environmental, social, and economic resources (Banister, Watson, \& Wood, 1997; Duany, Plater-Zyberk, \& Speck 2000; Krier 1998). Compact cities are characterized by the close juxtaposition of buildings and roads with limited interstitial space to insert greenery; mixed land use; and a union of form and function (Jenks et al., 1996). Proponents argue that compact cities are more energy efficient and less polluting because residents can live closer to shops and work and can walk, bike, or use public transport instead of their car. In social terms, compactness is also believed to increase social cohesion, equity, and accessibility (Duany et al., 2000; Krier 1998). Furthermore, compact cities are considered economically viable because infrastructure, such as roads and street lighting, can be provided cost-effectively per capita.

Neuman (2005) has recently reviewed empirical evidence as to whether compact cities represent a form of sustainable development. He concludes that the data are as yet inconclusive; some studies have shown a positive relation between compactness and sustainability while others have shown a negative relation. These inconsistent relationships may be partly due to methodological problems. Different studies have used different indicators of compactness and sustainability, and many studies have suffered from a lack of control over potential confounding factors. However, aside from these methodological issues, it seems apparent that compact building has not always fulfilled its promise of attaining a shift in community development toward more complete sustainability.

Explanations of the unsustainability of compact cities have focused mostly on the ineffectiveness of urban management (Jenks \& Burgess, 2000; Williams, Burton, \& Jenks, 2000). In particular, Mitlin and Satterthwaite (1996) have argued that "it is much more this failure of effective governance within cities that explains the poor environmental performance of so many cities rather than inherent characteristics of cities in general" (p. 51). However, there is increasing recognition that psychological factors play a role as well. In particular, it has been argued that there is an inherent tension or paradox between the notion of the compact city and people's desire for a spacious, green, and quiet environment (cf. Wiersinga, 1997). Several studies have shown that the urban green space is highly appreciated by residents and an important factor contributing to residential satisfaction (e.g., Bonaiuto, Aiello, Perugini, Bonnes, \& Ercolani, 1999). In compact cities with little green space, the desire for greener living environments may stimulate environmentally unsustainable developments such as urban fringe communities 
that are extremely dependent on automobiles for transportation (Kaplan \& Austin, 2004).

\section{Rural Romanticism or Need for Restoration?}

Proponents of the compact city model tend to attribute a desire to seek out the greener grasses of the suburbs to a romanticized view of rural life. This romanticized view bemoans the perceived disappearance of the simplicity and pureness of rural life, and idealizes nature in a naive manner. Such rural romanticism tends to go hand in hand with anti-urban sentiments (cf. Bunce, 1994). In particular in England and the United States, there is a widely shared belief that cities are, at best, a necessary evil, and a source of violence, social disorder, dirt, and sickness.

The pro-rural and anti-urban ideology gained additional influence during the 1800s when the devastating living conditions in cities in England during the industrial revolution provided the fuel for a mass social reform movement. This movement inspired a number of utopian urban visions, each with its own prophet, such as Ebenezer Howard and his Garden City; Le Corbusier and his Radiant City; Frank Lloyd Wright and his Broadacre City; and Daniel Hudson Burnham and his City Beautiful. Each of these sought some way to join the best of the city with the best of the countryside, and to address the worst of the city (the roots of the antiurban bias) and the worst of the countryside (which rendered some romantic views of nature naive). Some of these utopian visions clearly showed the then-prevailing enthusiasm for new construction and transportation technologies, and so did not anticipate the problems that in particular automobile transportation would come to pose.

Research and theory on restorative environments provide an alternative perspective on urban residents' desire for contact with nature. According to this perspective, people's desire for contact with green is more than naive rural romanticism; it may even reflect an evolutionary heritage. Authors such as Orians and Heerwagen (1992) and Kaplan and Kaplan (1989) have proposed that human appreciation of contact with nature may in part be a distant effect of the conditions under which early humans evolved. In the world they inhabited, it was of vital importance to approach nonthreatening objects and situations that provided shelter, food, and other basic necessities, and to evaluate positively informational characteristics of the environment that supported basic functions such as wayfinding. As a result, modern humans are still born with a predisposition to like or prefer certain features common to natural but not to urban or other built environments. This preference for nature has remained adaptive even for people who live in cities. Urbanites must often struggle to meet the demands of work, family, and other obligations against the backdrop of an environment that itself may contribute to a chronic experience of stress. Freely sought out contact with nature can provide some immediate relief from the demands of city life, by providing opportunities for 
the renewal of cognitive resources and psychophysiological response capabilities (e.g., Hartig, 2004; Kaplan \& Kaplan, 1989; Ulrich, 1983, 1993).

Research on restorative environments has proceeded along several lines, four of which will be discussed in the next sections. A first line of research has shown that people tend to perceive natural environments as more restorative than urban environments. A second line has demonstrated that people's environmental preferences are influenced by their restoration needs and beliefs about where restoration can best take place. A third line of research has provided evidence that contact with natural environments can actually promote restoration from stress and mental fatigue. And finally, a fourth line of research has studied the health impacts of contact with and access to natural environments.

\section{On the Nature of Beliefs about Nature}

It appears that people in urbanized societies commonly believe that contact with nature provides them with restoration from stress and fatigue and improves their health and well-being. For example, in a recent nationwide survey among inhabitants of The Netherlands, $95 \%$ of the respondents indicated that they believed that a visit to nature is a useful way of obtaining relief from stress (Frerichs, 2004). In a large survey of residents in nine Swedish towns and cities, Grahn and Stigsdotter (2003) found that, when asked what they would recommend to a friend who was feeling stressed and worried, most respondents gave the first rank to taking a walk in the forest.

People's belief in the stress-reducing powers of nature can also be inferred from research on motives for outdoor recreation (e.g., Driver, Nash, \& Haas 1987; Knopf, 1987). This research has found that stress reduction, clearing the head, escape from civilization, and reflection on important life issues are among the most dominant motives. This type of motive has come to be identified with psychological restoration.

Attention restoration theory (ART; Kaplan \& Kaplan, 1989; Kaplan, 1995) provides a useful explanation for the presumed restorative qualities of nature. ART proposes that prolonged and/or intensive use of directed attention diminishes a person's capacity to ward off distractions. The person may then show signs of directed attention fatigue, such as difficulty concentrating, increased irritability, and an increased rate of errors on tasks that require concentration. Kaplan (1995) has described this condition as one that puts a person at greater risk of experiencing stress because he or she has less of a cognitive resource needed to manage everyday demands (cf. Lepore \& Evans, 1996). A stay in an environment that does not require reliance on directed attention allows the mentally fatigued person to rest the inhibitory mechanism on which directed attention depends and so to recover the capacity to direct attention.

According to ART, natural environments provide relatively good opportunities for psychological restoration, because transactions with natural environments 
possess several qualities that, in combination, emerge less commonly in other types of environment. First, being in nature gives a person a sense of being away from daily routines that impose demands on directed attention. Second, natural environments contain many esthetically pleasing stimuli, and they encourage processes of exploration and sense making, and these attract and hold a person's attention effortlessly and to some extent involuntarily. This quality, which is assumed to be rooted in evolutionary history, is called soft fascination. Furthermore, the natural environment allows a sense of extent, due to coherence in the experience of the environment and the scope for continued exploration. Finally, experiences in natural environments typically involve a high degree of compatibility - that is to say, what the person wants to do in the environment matches well with what the environment affords and what the environment requires.

Several groups of researchers have departed from ART in efforts to measure perceived restorative quality in environments (Bagot, 2004; Berto, 2005; Han, 2003; Hartig, Korpela, Evans, \& Gärling, 1997; Hartig, Mang, \& Evans, 1991, Study 2; Herzog, Maguire, \& Nebel, 2003; Korpela \& Hartig, 1996; Laumann, Gärling, \& Stormark, 2001). Many of these studies used comparisons of natural and urban environments in their validation strategies, and they found that, in general, people did perceive natural environments as more restorative than urban environments. For example, in a recent study, Berto (2005) asked volunteers to rate the restorative quality of slides of natural and urban environments. The slides with the highest ratings of restorativeness were all nature scenes of lakes, rivers, the sea, and hills, while the slides with the lowest ratings of restorativeness were all urban scenes of city streets, industrial zones, and housing areas.

It bears emphasizing here that ART does not assume that restorative experiences only occur in natural environments, nor does research on restorative environments more generally assume that all urban public places lack restorative quality. Rather, there is appreciation for the fact that natural and built environments can have different restorative potentials with regard to the presence of restorative qualities in conjunction with personal needs and characteristics. For example, some natural environments may not well serve restoration because they are perceived as dangerous (Herzog \& Kutzli, 2002; Van den Berg \& Ter Heijne, 2005), while some urban environments may well support restoration because, in addition to possessing some degree of restorative quality, they are readily accessible and thus compatible with the limited time budgets of many urbanites (Scopelliti \& Giuliani, 2004).

\section{Restoration Needs as Drivers of Environmental Preference}

People not only perceive natural environments as more restorative than urban environments, they also tend to perceive natural environments as more beautiful. A large number of studies with samples of European, North American, and Asian 
adults have shown that photographs of natural scenes consistently receive higher ratings of preference or scenic beauty than photographs of urban scenes (see Ulrich,1993, for an overview). Perceived beauty seems to be closely intertwined with perceived restorative quality. Several studies have documented strong relations between measures of preference or scenic beauty and perceived restorative quality (e.g., Purcell, Peron, \& Berto, 2001).

The link between perceived restorative quality and environmental preference might lead one to suppose that the common preference for natural over urban environments can at least in part be explained by the belief that restoration will take place more easily in natural than in urban environments (e.g., Kaplan, 1995). We have tested this general hypothesis in a series of three experiments, in which we manipulated degree of attentional fatigue to examine how the attitude toward walking in natural and urban environments varied with the need for restoration (Hartig \& Staats, 2006; Staats \& Hartig, 2004; Staats, Kieviet, \& Hartig, 2003).

In the first two experiments (Staats \& Hartig, 2004; Staats et al., 2003) attentional fatigue was experimentally manipulated by asking Dutch students to imagine themselves as either extremely mentally fatigued or fully fresh and alert. In the third experiment (Hartig \& Staats, 2006) we used a naturalistic fatigue induction instead of scenarios. Swedish students participated in the experiment either in the morning before a lecture, when they were still fresh, or in the afternoon after a long lecture, when they were fatigued. The remainder of the procedure was similar for all three experiments. Students took a simulated "walk" through a forest or city center by watching a series of slides. Next, they rated how pleasant, agreeable, and so forth they would find such a walk in their current (fresh or fatigued) condition. They also rated the likelihood of restoration given a 1-hour walk in the environment just shown.

The results are shown in Figure 1. In general, the attitude toward walking for 1 hour in the forest was more positive than the attitude toward walking for 1 hour in the city center. However, all three studies showed that the difference in attitude toward walking in the forest versus city was greater among those in the "Fatigue" condition than it was among those in the "No Fatigue" condition. Notably, this interactive effect of fatigue and environment on attitude was weaker in Experiment 3, which can be understood from the smaller difference in mental fatigue across conditions.

In all three studies, restoration outcomes were evaluated more positively by those in the "Fatigue" condition than by those in the "No Fatigue" condition. Furthermore, restoration was judged to be much more likely while walking in the forest than while walking in the urban environment. Finally, likelihood of restoration correlated substantially and positively with the attitude toward walking in the given environment. Note that the correlation between the judged likelihood of restoration and attitude was positive for both the natural environment and the urban environment. That is, to the extent that people had a positive attitude toward 


\section{Experiment 1}

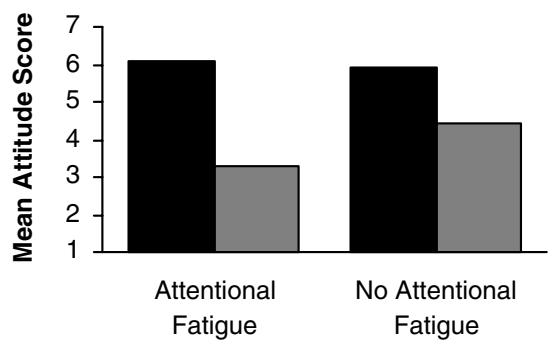

Experiment 3

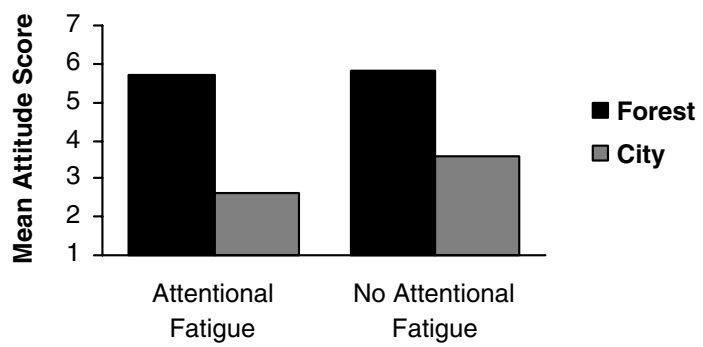

Experiment 2

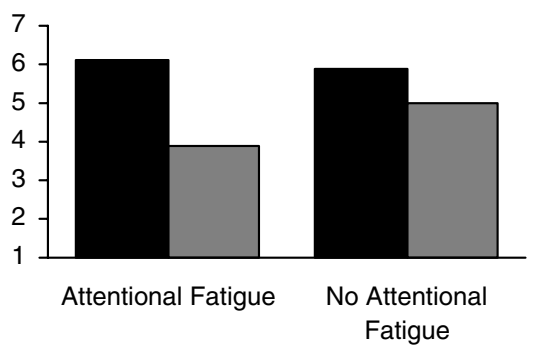

Fig. 1. Attitude toward walking in the given environment as a function of the type of environment and the level of attentional fatigue in three studies. A higher score indicates a more positive attitude. Based on Staats et al. (2003), Staats and Hartig (2004), and Hartig and Staats (2006).

walking in the urban environment, they also saw some possibility for restoration there.

In sum, these three experiments show consistently that the need for, and perceived likelihood of, restoration from mental fatigue together play a role in shaping the relative preference for natural over urban environments. The question then becomes whether people's expectations of restoration in natural environments hold true.

\section{Restorative Effects of Nature}

As we noted in our introduction, restorative effects of contact with nature have been demonstrated in a growing number of studies. Systematic reviews of the studies done to date have recently become available (Health Council of The Netherlands, 2004; Van den Berg, 2005). These reviews have covered roughly 20 trueand quasi-experimental studies. The studies differ in the way in which participants were exposed to environments (passive viewing of real or simulated environments vs. active entry into actual environments), antecedent conditions (mental fatigue 
vs. stress/anxiety), and the type of measures used (cognitive, physiological, and/or affective). Nevertheless, all of these studies found greater restorative effects of a natural environment compared to a comparison (usually urban) environment on at least one indicator of restoration.

Two of our own experimental studies help us speak directly to issues that we have raised with regard to access to restorative natural settings as a feature of urban sustainability. The first of these studies involved tracking psychophysiological stress recovery and directed attention restoration over time in natural and urban settings (Hartig, Evans, Jamner, Davis, \& Gärling, 2003). In this field experiment, all of the 112 young adult participants faced the demand of driving to a field site. On arrival, half of them completed demanding tasks, increasing the degree of their attentional fatigue just prior to the environmental treatment. The treatment had a 10-minute seated-indoors phase and a 50-minute walkingoutdoors phase. In the natural environment, the two phases were sitting in a room with tree views, then walking in a nature reserve. In the urban environment, the two phases were sitting in a room without views, then walking in an urban area. Repeated measures of emotion and attention were collected before, during, and after the treatment. Systolic and diastolic blood pressure measures were collected every 10 minutes, with an additional measure obtained during the seated treatment.

The results of this experiment showed that, after the drive or the tasks, sitting in a room with tree views promoted more rapid decline in diastolic blood pressure than sitting in a viewless room (Figure 2). Subsequently, walking in a nature reserve initially fostered blood pressure change that indicated greater stress reduction than afforded by walking in the urban surroundings. Performance on an attentional test improved slightly from the pretest to the midpoint of the walk in the nature reserve, but suffered in the urban setting. Positive affect increased and anger decreased in the nature reserve by the end of the walk, while the opposite pattern emerged in the urban environment.

In general, the findings from this experiment support the widely held belief that natural surroundings can better aid the psychological restoration of people living in cities than an urban environment relatively devoid of nature. The blood pressure results also illustrate two more specific points. First, they speak to the benefits of two forms of contact with nature, one involving passive viewing through a window (as studied by, for example, Kaplan, 2001), and the other involving movement through the environment while walking. Arguably, both of these forms of engagement are important to the urban sustainability effort. Adult urban residents normally spend the greatest part of their waking life indoors, either at home or at work. Views from indoors onto nature can support micro-restorative experiences that interrupt stress arousal or the depletion of attentional capacity. Similarly, when moving through the environment from one place to another, passage through a natural setting may provide a respite that, although brief, nonetheless interrupts 

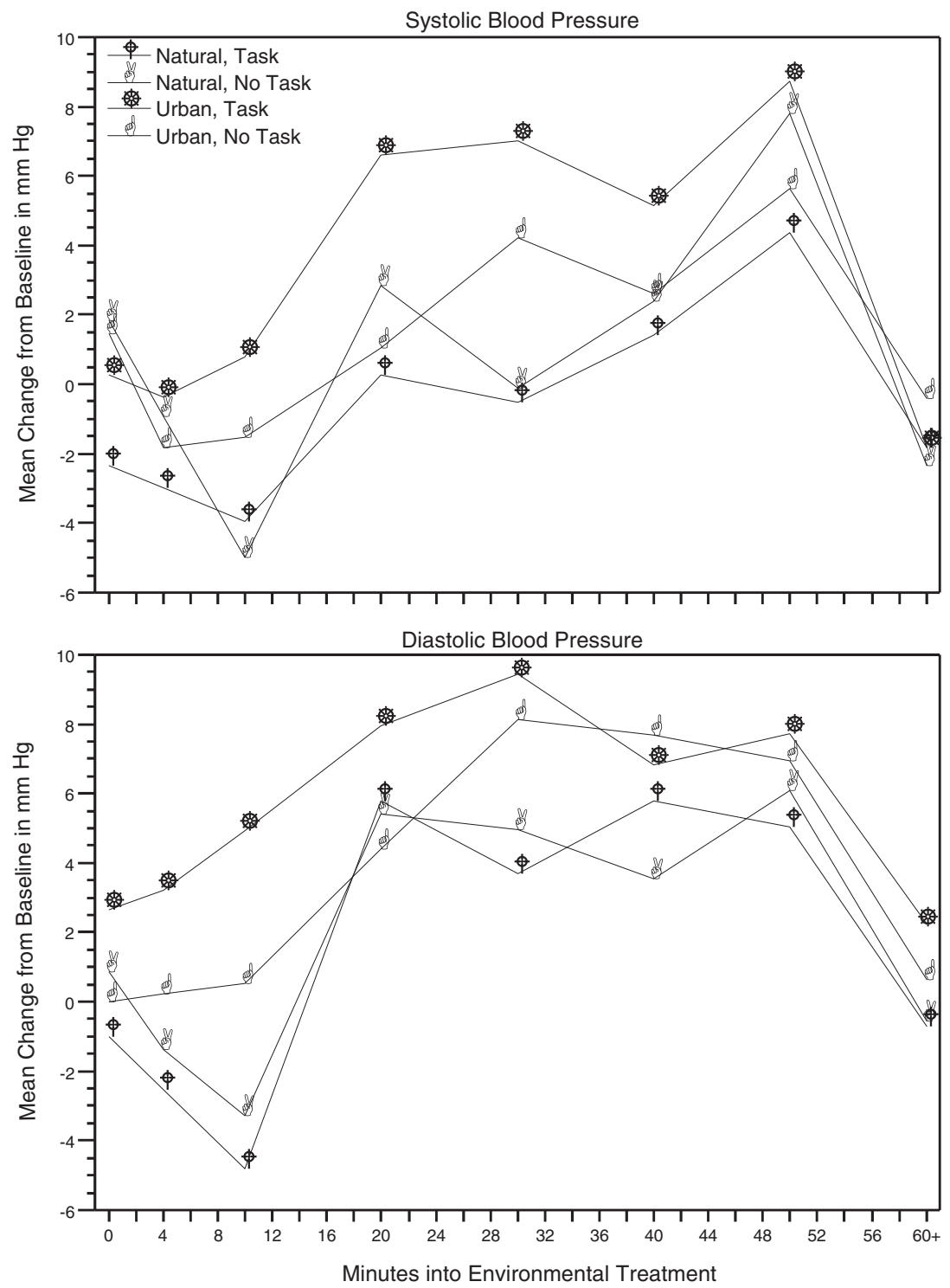

Fig. 2. Change in systolic (top panel) and diastolic (bottom panel) blood pressure relative to baseline as a function of environment and pretreatment task condition. The reading at 0 minutes marks either the first reading in the field lab following the drive or the end of the task. The readings at 4 and 10 minutes occurred while subjects sat in a room with window views of trees and vegetation or in a viewless room. The readings at 20,30, 40, and 50 minutes occurred during a walk in a nature reserve or an area of medium-density urban development. The readings at $60+$ minutes occurred while subjects again sat in a room with window views of trees or in a viewless room. From Hartig et al. (2003). 
a process of resource depletion. Frequent, brief restorative experiences may, over the long run, offer cumulative benefits.

The second of our studies that we want to emphasize was carried out in a laboratory (Van den Berg et al., 2003). The 114 participants viewed a frightening movie, and then were shown a 7-minute video simulating a walk through either a natural (two variants) or a built environment (also two variants). Participants' mood ratings were assessed before and after they viewed the frightening movie, and again after viewing the environmental video. Participants also rated the beauty of the environment shown and performed a test of concentration after viewing the environmental video. The results showed that viewing the natural environments elicited greater improvement in mood and marginally better concentration than viewing the built environments. In addition, participants rated the natural environments as more beautiful than the built environments. Mediational analyses revealed that affective restoration accounted for a statistically significant proportion of the preference for natural over built environments (Figure 3). Thus, the results of this study indicate that the preference for natural over built environments can be partly explained by the restoration that people actually achieve while in them.

With the results of this experiment we thus come full circle. We have provided illustrative evidence that people tend to perceive greater restorative quality (framed in terms of ART) in predominantly natural versus predominantly built environments. We have also demonstrated that people's beliefs about where to achieve restoration, as well as their need for restoration in the given moment, shape their relative preferences for natural and urban settings. We have summarized the results of experimental studies that speak to the restorative effects that people differentially realize in the two types of settings. And we have provided some initial experimental evidence that the differential realization of restorative benefits feeds back into their environmental preferences.

\section{Stress, Health, and Restoration Opportunities}

Ineffective stress recovery may undermine physical health through chronic arousal, immune suppression, and other aspects of allostatic load (Linden et al., 1997; McEwen, 1998; Sapolsky, 2004). An inability to periodically renew one's capacity to focus may also impair work performance and interpersonal relations. Consistent with these notions, there is increasing evidence that residents of urban neighborhoods with poor living conditions and few environmental amenities for restoration display more symptoms of chronic stress and poor health independent of the individual characteristics of residents (Steptoe \& Feldman, 2001).

Thus far, research on restorative values of natural environments has paid little attention to negative health impacts of (chronic) stress that may result from lack of access to natural environments. Nevertheless, the relevance of natural environments for health is supported by a few studies that have shown a relationship 

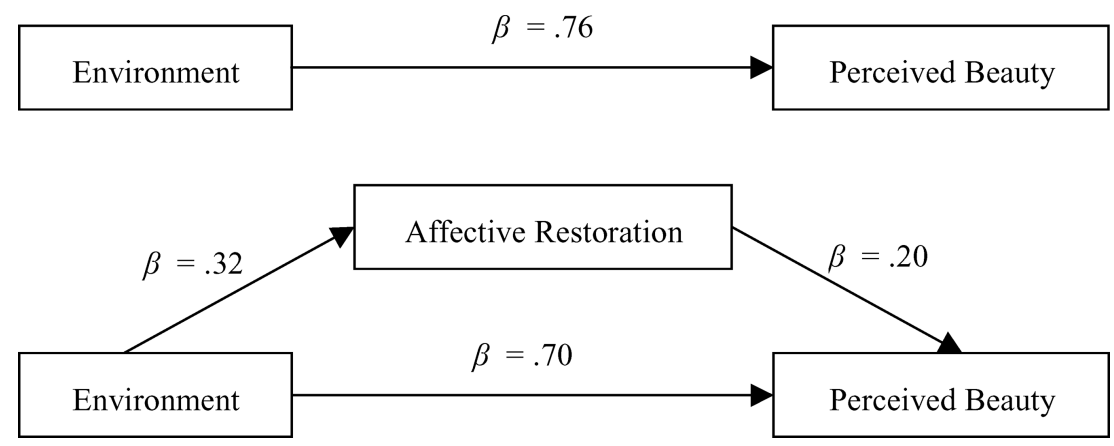

Fig. 3. Unmediated model (upper part) and mediated model (lower part) of the effect of environment (natural, built) on beauty. A Sobel test indicated that the mediation was significant, $z=2.27, p<.05$. From Van den Berg et al. (2003).

between presence of greenery and health indicators. For example, two large-scale epidemiological studies in The Netherlands (De Vries, Verheij, Groenewegen, \& Spreeuwenberg, 2003; Maas, Verheij, Groenewegen, De Vries, \& Spreeuwenberg, 2006) have revealed that residents of neighborhoods with abundant green space tend, on average, to self-report fewer health problems. These health benefits of green space were found not only with respect to green space close to home, but also with respect to greenery somewhat further away (1-3 kilometers from home). In both studies, the positive link between green space and health was found to be relatively marked among the elderly, housewives, and people from lower socioeconomic groups. The researchers attribute these findings to the fact that these groups spend a relatively large amount of time in the residential environment.

The results of the Dutch epidemiological studies allow for several interpretations of the mechanisms underlying the relationship between green space and health. These mechanisms may not only include the restorative quality of green space per se, but also health benefits of exercise (because presence of greenery may stimulate residents to walk or cycle), social contacts (green spaces may serve as a meeting point and in that way reduce health problems caused by social exclusion), or better air quality or less noise in greener environments. However, it seems likely that more than one of these mechanisms would be engaged in a typical outing into green space. For example, two friends will want to walk for exercise, and they will choose to do so in the park because it is pretty there and less hectic than the paths available in town.

There is still other evidence that restorative processes figure in the generation of health benefits of nature. In a well-known study of surgical patients, Ulrich (1984) found that patients who were assigned to a hospital room with a view of nature after their gallbladder surgery required fewer strong painkillers compared 
to those who were assigned to a room with a view of a brick wall. Patients with a view of trees also stayed in the hospital for approximately 1 day less than patients with a view of the brick wall, and they received less negative evaluations from the nursing staff. These findings speak of the relevance of restorative effects of viewing nature to clinically important health outcomes, as the hospital setting did not allow for explanations in terms of exercise, company, noise, or air quality.

\section{Design and Policy Implications}

The insights on relations between stress, restoration needs, and environmental preferences that we have offered in this article have potentially important implications for spatial planning and urban design. In particular, the finding that individuals in need of restoration display more nature-oriented preferences suggests that urbanites' appreciation of and demand for nature reflects a basic need that should not be discarded as mere "rural romanticism."

But what are the options? One option could involve rejection of urban compaction, achieved through a process of undifferentiated densification, as a wholly inappropriate urban form. People clearly want and can benefit from access to everyday nature, and over the long run they may suffer from crowded conditions. This option does not seem very viable. As pointed out in the introduction, compact cities have potential advantages for sustainability in terms of more efficient resource use and transport, and global environmental problems have become too serious to ignore these advantages. The idea that high-density cities should be abandoned altogether does not appear desirable from a psychological point of view either; high density also helps to make cities lively, vibrant, and desirable places to live for many people.

What we should look for, and aim for, then, are design and planning solutions that combine the benefits of the compact city for sustainability, without compromising people's need for green spaces that support restoration. Hence, perhaps a clever urban form or physical arrangement should be sought that is both sustainable and restorative. These ambitions have recently been adopted by a new approach in urban design, the so-called Green Urbanism approach (Beatley, 1999). This approach can be described as the greener version of another urban design approach, called New Urbanism. While New Urbanism focuses on making cities greener in a broad, ecological, or resource-conserving sense (using small amounts of energy, reducing emissions of carbon dioxide and toxic waste), Green Urbanism argues that cities must also be green in the sense of making nature (trees, parks, green rooftops) present. Thus far, Green Urbanists have been driven mostly by ecological motives. However, quality of life and restoration opportunities for urban residents are also considered important functions of urban greenery.

The design solutions of Green Urbanism involve creative, green infill options (such as green roofs, tree-lined parking lots, inner communal gardens, green 
building facades) as well as the creation of new urban towns and villages in close proximity to the existing transportation modes. The latter is particularly important with respect to the problem of urban sprawl. In most European countries, the policy for regulating urban sprawl has thus far been a "compact extension" program; that is, cities are extended in a very densely built way (e.g., Vinex neighborhoods in The Netherlands). The results of these compact extension policies have not always been good. The new neighborhoods are often too far away from the city center to inspire that vibrant-city feeling, and they are too dense and barren to evoke an atmosphere of rural living. Fortunately, this problem is increasingly recognized, and in The Netherlands, for example, plans for building new "rurban" residential environments near towns and cities have recently been launched (Van Dam, Bijlsma, Van Leeuwen, \& Pálsdóttir, 2005).

Of course, pending new design and planning solutions, there are many topics that need further research. For example, one topic that requires further attention concerns the influence of urban stressors on restoration needs and environmental preferences. As yet, it remains to be empirically demonstrated that the physical and psychological problems of urban living arouse restoration needs that continuously maintain and reinforce nature-oriented preferences. Future research also needs to address more applied issues. At present there is insufficient knowledge to translate findings into detailed guidelines for urban planning and design. In particular, little is known about the strength of the relationships, possible group differences, and the spatial conditions (size, type, layout of green space) that promote beneficial effects of nearby nature.

With respect to spatial conditions, a study conducted in Rome hints at some broad guidelines (Bonnes, Carrus, Bonaiuto, Fornara, \& Passafaro, 2004). This study showed that residential satisfaction and positive attitudes toward urban green spaces can be directly linked to the overall quantity/availability of these (in terms of amount per capita) but are somewhat independent of their overall quality/typology (in terms of biodiversity richness). That is, urban residents might be more concerned for having "more" green spaces available and less concerned for having green spaces of "higher ecological quality" (see also Bonnes, Uzzell, Carrus, \& Kelay, this issue). This notion is consistent with results of the Dutch study on relations between urban greenery and health by De Vries et al. (2003), which also showed that relations between self-reported health and amount of green space did not differ between different types of greenery. However, the literature is not unequivocal in this regard. For example, Kaplan (1985) found that residents of multifamily housing distinguished among different types of nearby nature, which contributed to measures of residential satisfaction in different ways. Different types of nature may assume more or less importance at different levels of density.

In closing, we would like to point out the remarkable commonalities in aims for cities globally. Whether achieved through a focus on urban compactness, urban greenery, or through other pathways, there remains an impressive level of 
agreement about the overall aims of sustainability on all continents. The desire for cities that are resource efficient and economically sustainable, and that provide a high quality of life is almost universal. Of course, the potential solutions are the key focus for research and debate. It seems that there is much to admire in the compact city model-with the right management and implementation methods. But as an answer to unsustainable cities it needs to be considered in relation to urban residents' need for restoration and the suitability of green environments for meeting that need.

\section{References}

Bagot, K. L. (2004). Perceived restorative components: A scale for children. Children, Youth and Environments, 14, 120-140.

Banister, D., Watson, S., \& Wood, C. (1997). Sustainable cities: Transport, energy, and urban form. Environment and Planning B: Planning and Design, 24(1), 125-143.

Beatley, T. (1999). Green urbanism: Learning from European cities. Washington: Island Press.

Berto, R. (2005). Exposure to restorative environments helps restore attentional capacity. Journal of Environmental Psychology, 25, 249-259.

Bonaiuto, M., Aiello, A., Perugini, M., Bonnes, M., \& Ercolani, A. P. (1999). Multidimensional perception of residential environment quality and neighborhood attachment in the urban environment. Journal of Environmental Psychology, 19, 331-352.

Bonnes, M., Carrus, G., Bonaiuto, M., Fornara, F., \& Passafaro, P. (2004). Inhabitants' environmental perceptions in the city of Rome within the framework for urban biosphere reserves of the UNESCO programme on man and biosphere. Annals of the New York Academy of Sciences 1023, 175-186.

Bonnes, M., Uzzell, D., Carrus, G., \& Kelay, T. (this issue). Inhabitants' and experts' assessments of environmental quality for urban sustainability.

Bunce, M. F. (1994). The countryside ideal: Anglo-American images of landscape. London and New York: Routledge.

Burgess, R. (2000). The compact city debate: A global perspective. In M. Jenks \& R. Burgess (Eds.), Compact cities: Sustainable urban forms for developing countries (pp. 9-24). London: E., \& F. N. Spon.

De Vries, S., Verheij, R. A., Groenewegen, P. P., \& Spreeuwenberg, P. (2003). Natural environmentshealthy environments? An exploratory analysis of the relationship between green space and health. Environment and Planning A, 35, 1717-1731.

Driver, B. L., Nash, R., \& Haas, G. (1987). Wilderness benefits: A state of knowledge review. In R.C. Lucas (Ed.), Proceedings, National Wilderness Research Conference: Issues, state-ofknowledge, future directions (General Technical Report INT-220, pp. 294-319). Ogden, UT: United States Department of Agriculture, Forest Service, Intermountain Research Station.

Duany, A., Plater-Zyberk, E., \& Speck, J. (2000). Suburban Nation. New York: North Point Press.

European Environment Agency (1995). Environment in the European Union 1995 : Report for the review of the Fifth Environmental Action Programme. Copenhagen: European Environment Agency.

Frerichs, R. (2004). Gezondheid en natuur; Een onderzoek naar de relatie tussen gezondheid en natuur [Health and nature; a research into the relation between health and nature]. Graveland (NL): Vereniging Natuurmonumenten.

Grahn, P., \& Stigsdotter, U. A. (2003). Landscape planning and stress. Urban Forestry and Urban Greening, 2, 1-18.

Habitat (2001). State of the world's cities report 2001. Nairobi: United Nations Center for Human Settlements.

Han, K. T. (2003). A reliable and valid self-rating measure of the restorative quality of natural environments. Landscape and Urban Planning, 64, 209-232. 
Hartig, T. (1993). Nature experience in transactional perspective. Landscape and Urban Planning, 25, $17-36$.

Hartig, T. (2004). Restorative environments. In C. Spielberger (Ed.), Encyclopedia of applied psychology (Vol. 3, pp. 273-279). San Diego, CA: Academic Press.

Hartig, T., Evans, G. W., Jamner, L. D., Davis, D. S., \& Gärling, T. (2003). Tracking restoration in natural and urban field settings. Journal of Environmental Psychology, 23, 109-123.

Hartig, T., Korpela, K., Evans, G. W., \& Gärling, T. (1997). A measure of restorative quality in environments. Scandinavian Housing and Planning Research, 14, 175-194.

Hartig, T., Mang, M., \& Evans, G. W. (1991). Restorative effects of natural environment experience. Environment and Behavior, 23, 3-26.

Hartig, T., \& Staats, H. (2006). The need for psychological restoration as a determinant of environmental preferences. Journal of Environmental Psychology, 26, 215-226.

Health Council of the Netherlands (2004). Nature and health. The influence of nature on social, psychological and physical well-being. Publication no. 2004/09. The Hague: Health Council of the Netherlands and Dutch Advisory Council for Research on Spatial Planning, Environment and Nature.

Herzog, T. R., \& Kutzli, G. E. (2002). Preference and perceived danger in field/forest settings. Environment and Behavior, 34, 819-835.

Herzog, T. R., Maguire, C. P., \& Nebel, M. B. (2003). Assessing the restorative components of environments. Journal of Environmental Psychology, 23, 159-170.

Jenks, M., \& Burgess, R. (2000). Compact cities: Sustainable urban forms for developing countries. London: E., \& F. N. Spon.

Jenks, M., Burton, E., \& Williams, K. (1996). The compact city: A sustainable urban form? London: E., \& F. N. Spon.

Kaplan, R. (1985). Nature at the doorstep: Residential satisfaction and the nearby environment. Journal of Architectural and Planning Research, 2, 115-127.

Kaplan, R. (2001). The nature of the view from home: Psychological benefits. Environment and Behavior, 33, 507-542.

Kaplan, R., \& Austin, M. E. (2004). Out in the country: Sprawl and the quest for nature nearby. Landscape and Urban Planning, 69, 235-243.

Kaplan, S. (1995). The restorative benefits of nature: Towards an integrative framework. Journal of Environmental Psychology, 15, 169-182.

Kaplan, S., \& Kaplan, R. (1989). The experience of nature: A psychological perspective. New York: Cambridge University Press.

Knopf, R. C. (1987). Human behavior, cognition and affect in the natural environment. In: D. Stokols \& I. Altman (Eds.), Handbook of environmental psychology (Vol. 1, pp. 783-825). New York: Wiley.

Korpela, K., \& Hartig, T. (1996). Restorative qualities of favorite places. Journal of Environmental Psychology, 16, 221-233.

Krier, L. (1998). Architecture: Choice or fate. Windsor: Andreas Papadakis.

Laumann, K., Gärling, T., \& Stormark, K. M. (2001). Rating scale measures of restorative components of environments. Journal of Environmental Psychology, 21, 31-44.

Lepore, S. J., \& Evans, G. W. (1996). Coping with multiple stressors in the environment. In: M. Zeidner \& N. S. Endler (Eds.), Handbook of coping: Theory, research, and applications (pp. 350-377). New York: Wiley.

Linden, W., Earle, T. L., Gerin, W., \& Christenfeld, N. (1997). Physiological stress reactivity and recovery: Conceptual siblings separated at birth? Journal of Psychosomatic Research, 42, 117 135.

Maas, J., Verheij, R. A., Groenewegen, P. P., de Vries, S., \& Spreeuwenberg, P. (2006). Green space, urbanity, and health: How strong is the relation? Journal of Epidemiology and Community Health, 60, 587-592.

McEwen, B. (1998). Protective and damaging effects of stress mediators. New England Journal of Medicine, 338, 171-179.

Mitlin, D., \& Satterthwaite, D. (1996). Sustainable development and cities. In C. Pugh (Ed.), Sustainability, the environment and urbanization (pp. 23-62). London: Earthscan. 
Neuman, M. (2005). The compact city fallacy. Journal of Planning Education and Research, 25, 11-26.

Orians, G. H., \& Heerwagen, J. H. (1992). Evolved responses to landscapes. In J.H. Barkow, L. Cosmides \& J. Tooby (Eds.), The adapted mind: Evolutionary psychology and the generation of culture (pp. 555-579). Oxford, UK: Oxford University Press.

Purcell, A. T., Peron, E., \& Berto, R. (2001). Why do preferences different between scene types? Environment and Behavior, 33, 93-106.

Sapolsky, R. M. (2004). Why zebras don't get ulcers. The acclaimed guide to stress, stress-related diseases, and coping. New York: Henry Holt and Company.

Scopelliti, M., \& Giuliani, M. V. (2004). Choosing restorative environments across the lifespan: A matter of place experience. Journal of Environmental Psychology, 24, 423-437.

Staats, H., \& Hartig, T. (2004). Alone or with a friend: A social context for psychological restoration and environmental preferences. Journal of Environmental Psychology, 24, 199-211.

Staats, H., Kieviet, A., \& Hartig, T. (2003). Where to recover from attentional fatigue: An expectancyvalue analysis of environmental preference. Journal of Environmental Psychology, 23, 147157.

Steptoe, A., \& Feldman, P. J. (2001). Neighborhood problems as sources of chronic stress: Development of a measure of neighborhood problems, and associations with socio- economic status and health. Annals of Behavioral Medicine, 23, 177-185.

Ulrich, R. S. (1983). Aesthetic and affective response to natural environments. In I. Altman \& J. F. Wohlwill (Eds.), Human behavior and environment: Advances in theory and research (Vol. 6, pp. 85-125). New York: Plenum Press.

Ulrich, R. S. (1984). View through a window may influence recovery from surgery. Science, 224, 420-421.

Ulrich, R. S. (1993). Biophilia, biophobia and natural landscapes. In S.R. Kellert, \& E.O. Wilson (Eds.). The biophilia hypothesis (pp. 73-137). Washington, DC: Island Press.

Van Dam, F., Bijlsma, L., Van Leeuwen, M., \& Pálsdóttir, H. L. (2005). De LandStad. Landelijk wonen in de netwerkstad [De LandStad, rural living in the network city, with summary in English]. Rotterdam/The Hague: NAi Uitgevers/RPB.

Van den Berg, A. E. (2005). Health impacts of healing environments: A review of the benefits of nature, daylight, fresh air and quiet in healthcare settings. Groningen: Foundation 200 years University Hospital Groningen.

Van den Berg, A. E., Koole, S. L., \& Van der Wulp, N. Y. (2003). Environmental preference and restoration: (How) are they related? Journal of Environmental Psychology, 23, 135-146.

Van den Berg, A. E., \& Ter Heijne, M. (2005). Fear versus fascination: Emotional responses to natural threats. Journal of Environmental Psychology, 25, 261-272.

Wiersinga, W. (1997). Compensation as a strategy for improving environmental quality in compact cities. Amsterdam: Bureau SME.

Williams, K., Burton, E., \& Jenks, M. (2000). Achieving sustainable urban form. London: E., \& F. N. Spon.

World Commission on Environment and Development (WCED) (1987). Our common future. New York: Oxford University Press.

AGNES VAN DEN BERG is an environmental psychologist who has specialized in research on interactions between people and the natural environment. She works as an associate professor and senior researcher at Wageningen University and Research Centre. Her work is focused on fundamental issues in human-nature relations, including health benefits of nature, individual differences in landscape preferences, and fear of nature. In addition, she is committed to the translation of theoretical insights into practical guidelines for planners, policy makers, and designers. 
TERRY HARTIG has more than 20 years experience in studying the health resource values of natural environments. He completed graduate training in environmental psychology and social ecology at the University of California at Irvine, and postdoctoral training in social epidemiology at the University of California at Berkeley. He currently works as an associate professor of applied psychology with the Institute for Housing and Urban Research and the Department of Psychology of Uppsala University in Sweden. He also holds an adjunct professor position with the Norwegian University of Life Sciences, where he participates in a universitywide Nature and Health initiative through affiliations with the Departments of Plant and Environmental Sciences and Landscape Architecture and Spatial Planning. Through 2008 he will lead a working group on physical and mental health benefits of nature experiences within a 22-country networking project funded by the European Science Foundation.

HENK STAATS is an assistant professor at the Department of Social and Organizational Psychology at Leiden University, the Netherlands. He teaches courses on environmental psychology, on attitudes, and on research methods. His research focuses on the joint and interactive effects of the social and the physical environment, and includes the study of environmental preferences, and the relations between pro-environmental attitudes and behaviors. He was recently a member of the advisory committee on Nature and Health for the National Health Council, is a board member of the Foundation for Wellbeing in Healthcare Institutions, and is a member of the Editorial Board of Applied Psychology: An International Review. 